\title{
INOVASI DALAM PEMBELAJARAN MATEMATIKA UNTUK MEMBEKALI MAHASISWA MENGHADAPI ERA REVOLUSI INDUSTRI 4.0
}

\author{
Isna Wardiah ${ }^{1)}$ dan Nurmahaludin ${ }^{2)}$ \\ 1), 2) T. Elektro, Politeknik Negeri Banjarmasin, \\ Jl. Brigjen H. Hasan Basri (Komp. ULM), Banjarmasin, 70123 \\ E-mail: ${ }^{1)}$ isnawardiah@poliban.ac.id
}

\begin{abstract}
Indonesia is facing an era of industri 4.0 that causes disruption in the labor market. Higher education institutions are obliged to equip students with life skills through lecturing process. It needs innovation for mathematics learning to give hard skills and soft skills for the students. Learning method that will be tested is Student team achievement division (STAD). The objective of this research is to equip students to face the era of industri 4 by improving soft skill and hard skill through STAD method. This is a classroom action research with students of IT study program of Poliban that learning mathematics II as the object. The study was conducted in two cycles. The dependent variables are Student's Soft skills (communication, discipline, teamwork, and creativity) and Students' hard skills (test scores). The independent variable is the STAD. Soft skills data were analyzed by calculating the mean of the softskill indicator and the hardskill data by measuring the mean of the test score. In the end, STAD cooperative learning improves students' soft skills, it can be seen from the observation value of each indicator which reaches $\geq 2.4$ with the criteria of "Good" results in cycle I and "Very Good" in cycle II. It also improves students' hard skills, $63.9 \%$ student reaches $>=65$ in cycle I and $87.1 \%$ in cycle II.
\end{abstract}

Keywords: Industrial Revolution 4.0, Hard skills, Soft skills, Mathematics learning,, STAD

\begin{abstract}
Abstrak
Indonesia tengah menghadapi revolusi industri 4.0 yang menyebabkan disrupsi pada pasar tenaga kerja, sehingga kualitas SDM sangat penting. Perguruan tinggi sebagai pencetak tenaga kerja wajib membekali mahasiswa dengan hard skills sekaligus soft skills melalui proses perkuliahan, termasuk perkuliahan matematika. Metode pembelajaran yang diujicoba adalah Student team achievment division (STAD). Tujuan penelitian adalah membekali mahasiswa menghadapi revolusi industri 4 dengan meningkatkan kemampuan soft skills dan hard skills melalui metode STAD. Objek penelitian adalah mahasiswa Teknik Informatika Poliban semester kedua TA 2017/2018 mata kuliah matematika II. Penelitian dilakukan dalam dua siklus, dengan tahapan Perencanaan, Tindakan, Observasi dan Refleksi. Variabel terikatnya yaitu: 1) Soft skills mahasiswa (keterampilan berkomunikasi, disiplin, kemampuan bekerjasama dalam tim, serta kreativitas); 2) Hard skills mahasiswa (nilai tes). Variabel bebasnya adalah model pembelajaran STAD. Data softskill dianalisa dengan menghitung rerata skor indikator softskill dalam lembar observasi. Data hard skills dianalisa dengan mengukur rerata nilai tes.
\end{abstract}


Kesimpulan didapat bahwa STAD mampu meningkatkan soft skills mahasiswa berupa teamwork, kedisiplinan, kreatifitas, dan komunikasi, hal ini terlihat dari nilai observasi tiap indikator yang mencapai $\geq 2.4$ dengan kriteria hasil "Baik" pada siklus I dan "Sangat Baik" pada siklus II. Begitu juga Hard skills mahasiswa pada mata kuliah matematika terapan Iidapat ditingkatkan, dimana 63,9\% mahasiswa memperoleh nilai $>=65$ pada siklus pertama menjadi $91.8 \%$ pada siklus kedua.

Kata kunci: Revolusi Industri 4.0, Hard skills, Soft skills, pembelajaran Matematika, STAD

\section{PENDAHULUAN}

Saat ini dunia tengah memasuki era revolusi industri 4.0, yang merupakan era disrupsi teknologi. Perkembangan ini membawa pengaruh dalam banyak aspek kehidupan baik positip maupun negatif (Hariastuti et al, 2017). Disatu sisi, revolusi industri lebih memudahkan manusia dalam menjalani hidupnya. Namun disisi lain, sumber daya manusia secara tidak langsung akan digantikan oleh mesin dan teknologi. Bahkan menurut Tritularsih (2017), teknologi telah menggeser peran manusia, revolusi industri secara fundamental akan mengubah cara kerja. Hal ini berdampak pada generasi selanjutnya yang perlu mengembangkan dirinya agar mampu bertahan. Indonesia, sebagai salah satu warga dunia, tentu tidak lepas dari permasalahan ini, sumber daya manusia (SDM) yang kompeten sangat dibutuhkan agar Indonesia tidak hanya menjadi penonton.

Pengembangan SDM yang berkualitas merupakan tugas dari sistem pendidikan (Ningrum, 2016), salah satunya perguruan tinggi (PT). PT sebagai pencetak tenaga kerja wajib membekali mahasiswa dengan hardskill-softskill melalui proses perkuliahan, termasuk juga perkuliahan matematika.

Pembelajaran matematika selama ini dianggap hanya mampu mengembangkan hardskill bagi mahasiswa, hanya terkait dengan rumus dan kemampuan berhitung saja. padahal banyak aspek softskill yang dapat dikembangkan dalam proses pembelajaran matematika. Oleh karena itu perlu inovasi agar pembelajaran matematika mampu memberikan hardskill sekaligus softskill bagi mahasiswa.

Tujuan penelitian adalah membekali mahasiswa menghadapi era revolusi industri 4.0 dengan meningkatkan kemampuan softskill dan hardskill mahasiswa melalui metode pembelajaran koperatif tipe Student Team Achievement Division (STAD). Penelitian dilaksanakan pada mata kuliah matematika terapan II di program studi teknik informatika Poliban Tahun akademik 2017/2018. Aspek Hardskill yang diteliti adalah tingkat pemahaman mahasiswa terhadap materi matematika terapan II yang diajarkan, sedangkan Aspek Softskill yang diteliti adalah kemampuan berkomunikasi (lisan), Disiplin, kemampuan bekerjasama dalam tim, serta kreativitas.

\section{METODE PENELITIAN}

Penelitian ini adalah Penelitian Tindakan Kelas (PTK), sehingga berdasar uraian dari Drs. Tatang Sunendar, M.Si (dalam Sudrajat, 2008) tentang langkahlangkah PTK, akan dilaksanakan dalam dua siklus. Setiap siklus dilaksanakan dalam empat kali pertemuan, terdiri atas tahapan: Perencanaan, Pelaksanaan, Observasi dan Refleksi. Siklus pertama akan membahas materi Limit Fungsi, sedangkan pada siklus kedua akan membahas materi Turunan (Diferensial). Di setiap akhir siklus akan diadakan tes 
akhir tindakan. Berikut diagram alir penelitian:

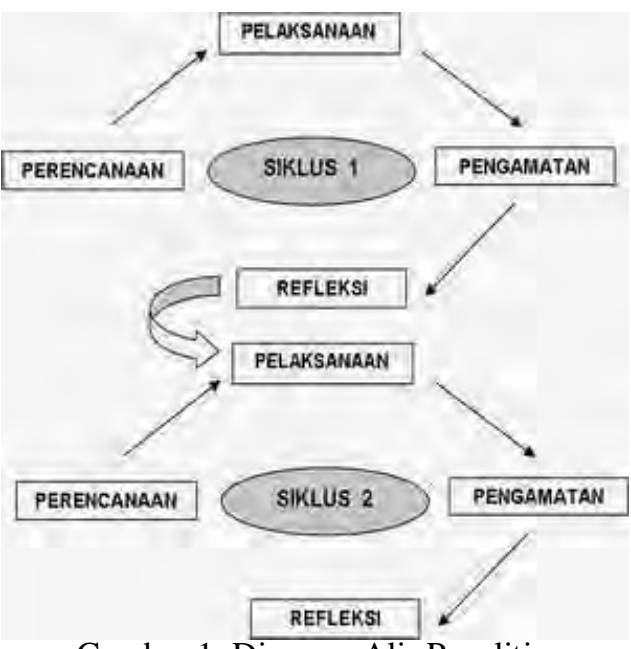

Gambar 1. Diagram Alir Penelitian

(Sumber: Wardiah, 2015)
Variabel terikatnya yaitu: 1) Kemampuan Softskill mahasiswa dengan indikator: keterampilan berkomunikasi, Disiplin, kemampuan bekerjasama dalam tim, serta kreativitas; 2) Kemampuan Hardskill mahasiswa berupa nilai tes. Sedangkan variabel bebasnya adalah model pembelajaran STAD. Rancangan Penelitian dapat diihat pada tabel berikut

Tabel 1 Rancangan Penelitian

\begin{tabular}{|c|c|c|}
\hline \multirow{18}{*}{$\begin{array}{c}\text { SIKLUS I } \\
\text { (Pertemuan I - } \\
\text { Pertemuan IV) }\end{array}$} & \multirow[t]{5}{*}{ Perencanaan } & $\begin{array}{l}\text { Menyusun Satuan Acara Perkuliahan mata kuliah Matematika terapan II } \\
\text { untuk pelaksanaan siklus 1, yakni Pertemuan I sampai Pertemuan IV }\end{array}$ \\
\hline & & Menyiapkan bahan ajar yang akan digunakan selama siklus 1 \\
\hline & & $\begin{array}{l}\begin{array}{l}\text { Mempersiapkankan format } \text { Observasi dan Format } \\
\text { (pertemuan I sampai IV) }\end{array} \\
\end{array}$ \\
\hline & & Menyiapkan soal Post-test Siklus 1 pada akhir pertemuan IV \\
\hline & & Menyiapkan sumber data dan media pembelajaran \\
\hline & \multirow{13}{*}{$\begin{array}{c}\text { Pelaksanaan } \\
\text { (Pertemuan I } \\
\text { - Pertemuan } \\
\text { IV) }\end{array}$} & Kegiatan Awal \\
\hline & & Mengkondisikan Mahasiswa \\
\hline & & Menyampaikan tujuan pembelajaran pada mahasiswa \\
\hline & & Memberikan motivasi kepada mahasiswa untuk bekerjasama \\
\hline & & Kegiatan Inti \\
\hline & & Dosen menjelaskan materi \\
\hline & & $\begin{array}{l}\text { Dosen membentuk kelompok dengan anggota } 2 \text { atau } 3 \text { orang mahasiswa } \\
\text { secara heterogen (campuran berdasar prestasi) }\end{array}$ \\
\hline & & $\begin{array}{l}\text { Dosen memberikan soal latihan yang telah disertakan dalam modul kepada } \\
\text { kelompok untuk dikerjakan oleh anggota-anggota kelompok }\end{array}$ \\
\hline & & $\begin{array}{l}\text { Mahasiswa mendiskusikan soal/tugas dan diharapkan saling membantu antar } \\
\text { anggota kelompok }\end{array}$ \\
\hline & & $\begin{array}{l}\text { Anggota kelompok yang mengerti tentang materi menjelaskan kepada } \\
\text { anggota yang lain dalam kelompok itu sampai mengerti }\end{array}$ \\
\hline & & $\begin{array}{lllll}\begin{array}{l}\text { Dosen membimbing } \\
\text { melaksanakan diskusi }\end{array} & \text { kelompok-kelompok belajar mahasiswa dalam } \\
\end{array}$ \\
\hline & & $\begin{array}{l}\text { Dosen meminta perwakilan mahasiswa dalam } \\
\text { mempresentasikan hasil kerja kelompok }\end{array}$ \\
\hline & & $\begin{array}{l}\text { Hasil tes digunakan sebagai hasil perkembangan individu dan keberhasilan } \\
\text { kelompok }\end{array}$ \\
\hline
\end{tabular}




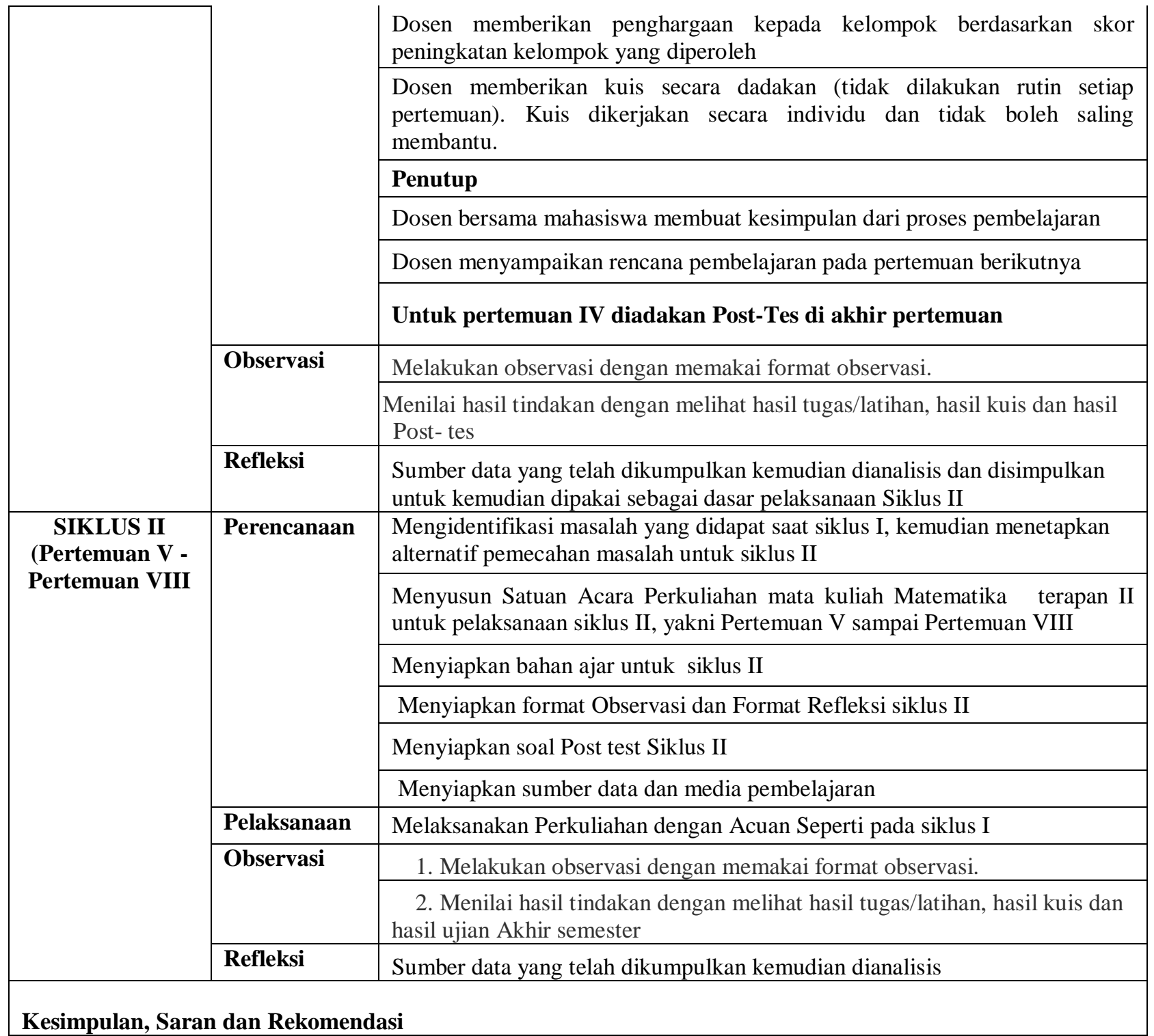

Data dikumpulkan melalui observasi dan tes. Data softskill dianalisa dengan menghitung rerata skor indikator softskill dalam lembar observasi. Data hardskill dianalisa dengan mengukur rerata nilai tes.

Kisi-kisi lembar observasi yang akan dibuat adalah:

Tabel 2 Kisi-kisi lembar observasi

\begin{tabular}{|c|c|c|c|}
\hline Variabel & Indikator & Item & $\begin{array}{l}\text { No. } \\
\text { Item }\end{array}$ \\
\hline \multirow{10}{*}{$\begin{array}{c}\text { Soft skill } \\
\text { mahasiswa }\end{array}$} & \multirow{5}{*}{$\begin{array}{c}\text { Kemampuan } \\
\text { bekerjasama } \\
\text { dalam tim }\end{array}$} & Membantu teman lain yang sedang mengalami kesulitan Pelajaran & 1 \\
\hline & & Mengingatkan teman jika belum mengerjakan tugas kelompok & 2 \\
\hline & & Memberikan kesempatan kepada teman untuk berbicara & 3 \\
\hline & & Mengerjakan tugas kelompok & 4 \\
\hline & & Mengekspresikan kegembiraan atas keberhasilan teman kelompok & 5 \\
\hline & \multirow[t]{5}{*}{ Kedisiplinan } & Disiplin terhadap waktu & 6 \\
\hline & & Tepat waktu dalam menyelesaikan tugas & 7 \\
\hline & & mengerjakan tugas sesuai prosedur & 8 \\
\hline & & melakukan diskusi kelompo secara tertib & 9 \\
\hline & & Fokus dengan pembelajaran di kelas & 10 \\
\hline
\end{tabular}




\begin{tabular}{lll}
\hline \multirow{2}{*}{ Kreativitas } & Memanfaatkan fasilitas untuk belajar & 11 \\
\cline { 2 - 3 } & Memiliki Referensi yang dijadikan sumber belajar & 12 \\
\cline { 2 - 3 } & Memberi gagasan terhadap suatu masalah & 13 \\
\cline { 2 - 3 } & Dapat memecahkan masalah/ Mengerjakan soal & 14 \\
\cline { 2 - 3 } & Mencoba cara baru dalam menyelesaikan soal matematika & 15 \\
\hline Kemampuan & Menangkap informasi yang disampaikan guru & 16 \\
\cline { 2 - 3 } & Bertanya maupun berdiskusi dengan dosen & 17 \\
\cline { 2 - 3 } & aktif dalam pembelajaran di kelas & 19 \\
\cline { 2 - 3 } & dapat mengendalikan ucapan & 20 \\
\cline { 2 - 3 } & Komunikatif dengan teman sekelompok & \\
\hline
\end{tabular}

Tipe kuesioner yang digunakan adalah Format Pasti (Fixed Format) dengan bentuk pertanyaan pilihan dengan penilaian (0) Sangat Kurang, (1) Kurang, (2) Cukup, (3) Baik, (4) Sangat Baik. Menghitung hasil observasi siswa dilakukan dengan penskoran :

1) Rumus menghitung rata-rata observasi setiap indikator kemampuan softskill mahasis

$$
\text { Rata-rata }=\frac{\text { Jumlah Skor Tiap Indikator }}{\text { Jumlah Siswa }}
$$

2) Rumus menghitung rata-rata observasi kemampuan softskill mahasiswa setiap siklus

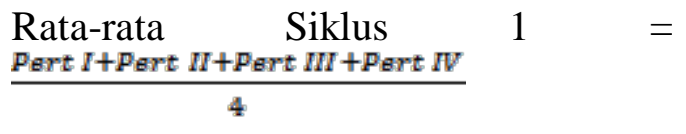

$\frac{\text { Rata-rata } \quad \text { Siklus } 2}{4}=$

Keterangan: Pert $n$ : Skor pertemuan ke- $n$

Kriteria penilaian:

$0 \leq$ rata-rata $<0,8$ : kemampuan softskill mahasiswa sangat kurang $0,8 \leq$ rata-rata $<1,6$ : kemampuan softskill mahasiswa kurang

$1,6 \leq$ rata-rata $<2,4$ : kemampuan softskill mahasiswa cukup

$2,4 \leq$ rata-rata $<3,2$ : kemampuan softskill mahasiswa baik

$3,2 \leq$ rata-rata $\leq 4$ : kemampuan softskill mahasiswa sangat baik

Kuis diadakan secara mendadak pada pertemuan tertentu untuk menguji kemampuan mahasiswa terhadap materi yang telah diberikan pada pertemuan

$\begin{array}{lcr}\text { sebelumnya. } \quad \text { Rata-rata } & \text { kuis tiap } \\ \text { mahasiswa tiap } & \text { siklus } & = \\ \frac{\text { total nilai kuis mahasiswa ybs }}{\text { jumlah kuis diadakan }} & \end{array}$

a. Indikator keberhasilan untuk observasi kemampuan softskill mahasiswa adalah apabila skor observasi tiap indikator keaktifan mahasiswa mencapai $\geq 2,4$ dengan kriteria keaktifan baik.

b. Indikator keberhasilan untuk tes adalah apabila nilai rata-rata kuis maupun post-tes mencapai $>=60$ dan hasil siklus II mengalami perbaikan dibandingkan dengan hasil siklus I.

\section{HASIL DAN PEMBAHASAN Hasil Observasi Untuk Mengetahui Soft Skill Mahasiswa}

Dalam proses pembelajaran, mahasiswa dibagi menjadi beberapa kelompok, beranggotakan 3 orang. Pembagian kelompok awal ditentukan oleh dosen berdasarkan penilaian hard skill dan soft skill mahasiswa pada semester sebelumnya. Penilaian hard skill didapat dari nilai matematika I mereka pada semester pertama, setiap kelompok dipadukan dari mahasiswa yg kemampuannya tinggi, sedang dan rendah. Harapannya, agar proses transfer ilmu dapat terjadi di dalam kelompok. Penilaian Soft skills awal didapat dari pengamatan yang telah dilakukan dosen pada semester pertama, walaupun masih secara umum, mahasiswa yang dikelompokkan ini disesuaikan karakternya, sehingga proses kerjasama dalam tim diharapkan dapat berlangsung 
dengan baik. Untuk kasus tertentu ada beberapa kelompok yang hanya beranggotakan dua orang.

Pembagian kelompok awal tersebut tidak bersifat mutlak, setelah proses berjalan, jika ada ketidakcocokan, anggota kelompok kemudian disusun ulang. Seperti pada kelas TI A ada anggota kelompok yang menolak dipasangkan karena merasa tidak cocok, dan kelas TI C dimana ada kelompok yang sangat pasif (saat observasi, tampak kelompok ini diam saja saat sesi diskusi antar anggota kelompok, analisis peneliti hal ini karena ketiga anggota kelompok sama- sama pendiam dan tidak akrab). Ini menunjukkan indikator soft skill sebagian mereka berupa kemampuan berkomunikasi, dan kemampuan bekerjasama dalam tim masih rendah, namun ini hanya terjadi pada beberapa orang mahasiswa saja, sehingga secara umum masih dalam kategori baik. Untuk mengatasi hal tersebut, pada awal pertemuan kedua, beberapa kelompok dirombak anggotanya dengan mendengarkan keinginan dari mahasiswa namun tetap sesuai ketentuan perbedaan kemampuan antar anggota kelompok. Pada pertemuan pertama ini mahasiswa masih belum beraktivitas sesuai yang diharapkan, disipln terhadap waktu masih kurang karena ada beberapa mahasiswa yang datang terlambat di awal perkuliahan, mereka juga belum memiliki sumber referensi belajar, padahal modul ajar dosen sudah ada dan bisa dipinjam/fotokopy dari perpustakaan kampus, hal ini tentu mempengaruhi penilaian kreatifitas mereka pada lembar observasi. Mereka juga masih tergolong pasif, mengharap pembelajaran melalui ceramah dosen dan sebagian besar masih menunggu instruksi-instruksi dari dosen pengajar. Untuk itu dosen memberikan arahan kegiatan-kegiatan yang harus mereka lakukan untuk pertemuan selanjutnya, bahkan teguran bagi mahasiswa yang tadinya datang terlambat, agar pembelajaran lebih efektif.

Pada pertemuan II sampai IV pada siklus I, secara bertahap tampak perubahan menuju lebih baik. Arahanarahan yang diberikan sudah mulai dipahami dan dilaksanakan oleh mahasiswa. Kerjasama dalam tim mulai terbangun dengan lebih baik, Komunikasi baik didalam kelompok, antar kelompok dan terhadap dosen mulai lancar, walaupun masih ada beberapa mahasiswa yang terlihat ragu atau takut untuk bertanya saat kesulitan mengerjakan tugas. Pada evaluasi siklus I, indikator soft skills yang bernilai rendah dari indikator lain adalah kreatifitas. Oleh karena itu, pada tahap perencanaan siklus II, peneliti merancang cara pemberian materi pelajaran yang merangsang mahasiswa untuk mencari cara/ metode sendiri dalam mengerjakan soal, kemudian mengemukakan gagasan mereka di depan kelas.

Observasi pada siklus II menunjukkan indikator soft skills mahasiswa lebih baik, mahasiswa semakin kompak dan terbiasa bekerjasama dalam kelompoknya bahkan juga antar kelompok. Mereka juga lebih disiplin, mampu mengerjakan soal sesuai prosedur. Untuk indikator kreatifitas, cara yang diterapkan dosen ternyata cukup efektif, mahasiswa secara berkelompok mulai suka mencoba coba mencari metode memecahkan masalah (soal) diluar cara yang diajarkan dosen, keberhasilan mereka kemudian dipaparkan didepan kelas sehingga menimbulkan kebanggan tersendiri bagi kelompok yang berhasil.

Melalui penerapan pembelajaran kooperatif tipe STAD tersebut, tampak bahwa proses pembelajaran berpusat pada mahasiswa dengan interaksi multiarah mampu meningkatkan kemampuan mereka bekerjasama, kedisiplinan, kreatifitas serta kemampuan berkomunikasinya. 
Tabel 3. Hasil Observasi Terhadap Soft skill pada Siklus I

\begin{tabular}{ccccccc}
\hline indikator & P1 & P2 & P3 & P4 & Rerata/ Item & Kriteria Hasil \\
\hline Item 1 & 2.5 & 3.2 & 3.3 & 3.6 & $\mathbf{3 . 1 5}$ & Baik \\
Item 2 & 2 & 2.8 & 3.1 & 3.3 & $\mathbf{2 . 8}$ & Baik \\
Item 3 & 2.4 & 2.7 & 2.7 & 2.8 & $\mathbf{2 . 6 5}$ & Baik \\
Item 4 & 2.5 & 2.9 & 2.9 & 3.1 & $\mathbf{2 . 8 5}$ & Baik \\
Item 5 & 2.2 & 3.3 & 3.3 & 3.6 & $\mathbf{3 . 1}$ & Baik \\
Item 6 & 1.9 & 2.5 & 2.5 & 3 & $\mathbf{2 . 4 7 5}$ & Baik \\
Item 7 & 2 & 2.6 & 2.8 & 3 & $\mathbf{2 . 6}$ & Baik \\
Item 8 & 2.2 & 2.3 & 3.1 & 3.4 & $\mathbf{2 . 7 5}$ & Baik \\
Item 9 & 2.3 & 2.4 & 2.4 & 3.0 & $\mathbf{2 . 5 2 5}$ & Baik \\
Item 10 & 2.3 & 2.5 & 3 & 3.3 & $\mathbf{2 . 7 7 5}$ & Baik \\
Item 11 & 1.3 & 2.2 & 2.5 & 2.5 & $\mathbf{2 . 1 2 5}$ & Cukup \\
Item 12 & 1 & 2 & 2.3 & 2.3 & $\mathbf{1 . 9}$ & Cukup \\
Item 13 & 1.6 & 2.3 & 2.5 & 3 & $\mathbf{2 . 3 5}$ & Cukup \\
Item 14 & 2 & 2.4 & 2.8 & 3.1 & $\mathbf{2 . 5 7 5}$ & Baik \\
Item 15 & 2.3 & 2.4 & 2.5 & 2.5 & $\mathbf{2 . 4 2 5}$ & Baik \\
Item 16 & 2.4 & 2.5 & 2.5 & 2.9 & $\mathbf{2 . 5 7 5}$ & Baik \\
Item 17 & 2.3 & 2.7 & 2.8 & 2.8 & $\mathbf{2 . 6 5}$ & Baik \\
Item 18 & 2.5 & 2.8 & 3 & 3 & $\mathbf{2 . 8 2 5}$ & Baik \\
Item 19 & 2.6 & 2.8 & 2.8 & 3 & $\mathbf{2 . 8}$ & Baik \\
Item 20 & 2.1 & 2.7 & 2.7 & 3 & $\mathbf{2 . 6 2 5}$ & Baik
\end{tabular}

Sumber: Data yang diolah, 2018

Rata-rata untuk siklus $1=\frac{P_{1}+P_{2}+P 3+P 4}{4}=2.63$

Tabel 4. Hasil Observasi Terhadap Soft skill pada Siklus II

\begin{tabular}{ccccccc}
\hline indikator & P5 & P6 & P7 & P8 & Rerata/Item & Kriteria Hasil \\
\hline Item 1 & 3.6 & 3.6 & 3.5 & 3.6 & $\mathbf{3 . 5 7 5}$ & Sangat Baik \\
Item 2 & 3.2 & 3.3 & 3.4 & 3.3 & $\mathbf{3 . 3}$ & Sangat Baik \\
Item 3 & 3 & 3.2 & 3.2 & 3.4 & $\mathbf{3 . 2}$ & Sangat Baik \\
Item 4 & 3.1 & 3 & 3.2 & 3.4 & $\mathbf{3 . 1 7 5}$ & Baik \\
Item 5 & 3.6 & 3.6 & 3.6 & 3.7 & $\mathbf{3 . 6 2 5}$ & Sangat Baik \\
Item 6 & 2.9 & 3.2 & 3.4 & 3.2 & $\mathbf{3 . 1 7 5}$ & Baik \\
Item 7 & 2.8 & 3 & 3 & 3.2 & $\mathbf{3}$ & Baik \\
Item 8 & 3.4 & 3.5 & 3.5 & 3.4 & $\mathbf{3 . 4 5}$ & Sangat Baik \\
Item 9 & 3.0 & 3.0 & 3.3 & 3.4 & $\mathbf{3 . 1 7 5}$ & Baik \\
Item 10 & 3 & 3.2 & 3.2 & 3.3 & $\mathbf{3 . 1 7 5}$ & Baik \\
Item 11 & 3 & 3.1 & 3 & 3.4 & $\mathbf{3 . 1 2 5}$ & Baik \\
Item 12 & 2.5 & 2.5 & 2.5 & 2.7 & $\mathbf{2 . 5 5}$ & Baik \\
Item 13 & 3 & 3.2 & 3.1 & 3.4 & $\mathbf{3 . 1 7 5}$ & Baik \\
Item 14 & 3 & 3.1 & 3.3 & 3.4 & $\mathbf{3 . 2}$ & Sangat Baik \\
Item 15 & 3.3 & 3.1 & 3.3 & 3 & $\mathbf{3 . 1 7 5}$ & Baik \\
Item 16 & 3 & 3.3 & 3.2 & 3.1 & $\mathbf{3 . 1 5}$ & Baik \\
Item 17 & 3 & 3.3 & 3.3 & 3.4 & $\mathbf{3 . 2 5}$ & Sangat Baik \\
Item 18 & 2.9 & 3.3 & 3.3 & 3.5 & $\mathbf{3 . 2 5}$ & Sangat Baik \\
Item 19 & 3 & 3 & 3.2 & 3.2 & $\mathbf{3 . 1}$ & Baik \\
Item 20 & 3.2 & 3.3 & 3.2 & 3.2 & $\mathbf{3 . 2 2 5}$ & Sangat Baik \\
\hline Rerata/ pertemuan & $\mathbf{3 . 0 7 5}$ & $\mathbf{3 . 1 9}$ & $\mathbf{3 . 2 3 5}$ & $\mathbf{3 . 3 1}$ & & \\
\hline Sig
\end{tabular}

Sumber: Data yang diolah, 2018

Rata-rata untuk siklus II $=\frac{P 4+P 6+P 7+P 8}{4}=3.2$ 
Jika dikelompokkan berdasarkan indikatornya, dapat dilihat sebagai berikut:

Tabel 5. Perbandingan Rerata tiap Indikator Soft skill pada siklus I dan II

\begin{tabular}{|c|c|c|c|c|}
\hline \multirow[t]{2}{*}{ Indikator } & \multicolumn{2}{|c|}{ Siklus I } & \multicolumn{2}{|c|}{ Siklus II } \\
\hline & rerata per Item & rerata per Indikator & rerata per Item & rerata per Indikator \\
\hline \multirow{5}{*}{$\begin{array}{l}\text { Kemampuan } \\
\text { bekerjasama dalam } \\
\text { tim }\end{array}$} & 3.15 & \multirow[t]{5}{*}{2.91} & 3.575 & \multirow[t]{5}{*}{3.375} \\
\hline & 2.8 & & 3.3 & \\
\hline & 2.65 & & 3.2 & \\
\hline & 2.85 & & 3.175 & \\
\hline & 3.1 & & 3.625 & \\
\hline \multirow[t]{5}{*}{ Kedisiplinan } & 2.475 & \multirow[t]{5}{*}{2.625} & 3.175 & \multirow[t]{5}{*}{3.195} \\
\hline & 2.6 & & 3 & \\
\hline & 2.75 & & 3.45 & \\
\hline & 2.525 & & 3.175 & \\
\hline & 2.775 & & 3.175 & \\
\hline \multirow[t]{5}{*}{ Kreativitas } & 2.125 & \multirow[t]{5}{*}{2.275} & 3.125 & \multirow[t]{5}{*}{3.045} \\
\hline & 1.9 & & 2.55 & \\
\hline & 2.35 & & 3.175 & \\
\hline & 2.575 & & 3.2 & \\
\hline & 2.425 & & 3.175 & \\
\hline \multirow{5}{*}{$\begin{array}{l}\text { Kemampuan } \\
\text { berkomunikasi }\end{array}$} & 2.575 & \multirow[t]{5}{*}{2.695} & 3.15 & \multirow[t]{5}{*}{3.195} \\
\hline & 2.65 & & 3.25 & \\
\hline & 2.825 & & 3.25 & \\
\hline & 2.8 & & 3.1 & \\
\hline & 2.625 & & 3.225 & \\
\hline
\end{tabular}

Berdasarkan hasil observasi terlihat peningkatan yang cukup signifikan antara siklus I ke II. Rata-rata skor soft skill mahasiswa naik dari 2,6 (kategori "Baik") pada siklus pertama menjadi 3,2 (kategori "Sangat Baik"). Hal ini karena mahasiswa sudah mulai terbiasa dengan metode pembelajaran kooperatif tipe STAD yang diterapkan. Jika dilihat secara spesifik tiap indikatornya, untuk kemampuan bekerjasama dalam tim, kedisiplinan, dan kemampuan berkomunikasi, nilai reratanya naik dari kategori "baik" menjadi "Sangat Baik", sedangkan untuk indikator kreativitas, naik dari "Cukup" menjadi "Baik".

\section{Hasil Tes Untuk Mengetahui Hard skill mahasiswa}

Selama PTK, telah diadakan empat kali tes, yakni pada akhir pertemuan kedua dan keempat pada siklus I, dan akhir pertemuan enam dan delapan pada siklus II. Berikut rangkuman rata-rata nilai tes dari 122 mahasiswa.
Tabel 6. Rerata Hasil Tes sebagai Indikator Hard skill matematika

\begin{tabular}{|c|c|c|c|c|}
\hline & \multicolumn{2}{|c|}{ Siklus I } & \multicolumn{2}{c|}{ Siklus II } \\
\hline & Quiz 1 & Post test 1 & Quiz 2 & Post Test 2 \\
\hline $\begin{array}{c}\text { Rata- } \\
\text { rata nilai }\end{array}$ & 69.0 & 71.2 & 81.4 & 81.8 \\
\hline
\end{tabular}

Pada siklus pertama, dilakasanakan dua kali tes, dari data yang didapat diketahui bahwa 73 orang dari 122 mhasiswa memperoleh nilai 60 keatas, ini artinya $63.9 \%$ mahasiswa objek penelitian telah memiliki nilai yang baik. Berdasarkan evaluasi siklus I, peneliti melanjutkan siklus kedua dengan mengadakan beberapa perbaikan metode pembelajaran, lebih mengintensifkan perhatian pada kelompok atau individu yang masih bermasalah nilai. Pada siklus kedua diadakan dua kali tes. Hasilnya, 112 orang dari 122 mahasiswa mendapatkan nilai 60 keatas, atau sekitar $91.8 \%$. Ini artinya terjadi peningkatan sebesar 27.9 \% dari hasil di siklus I. 


\section{KESIMPULAN DAN SARAN}

1. Model pembelajaran kooperatif tipe STAD mampu meningkatkan soft skill mahasiswa berupa kemampuan bekerjasama dalam tim, kedisiplinan, kreatifitas, dan kemampuan berkomunikasi. Hal ini terlihat dari nilai hasil observasi tiap indikator yang mencapai $\geq 2.4$ dengan kriteria hasil "Baik" pada siklus I dan "Sangat Baik" pada siklus II

2. Model pembelajaran kooperatif tipe STAD mampu meningkatkan Hard skill mahasiswa pada mata kuliah matematika terapan II. Ini dapat dilihat dari hasil bahwa 63,9\% mahasiswa memperoleh nilai $>=65$ pada siklus pertama dan $91.8 \%$ pada siklus kedua

\section{DAFTAR PUSTAKA}

Hariastuti, R.T., Prawitasari, J.E., Handarini, D.M., \& Atmoko, A. (2017). The development of critical thinking skills based of patrap triloka's Ki Hadjar Dewantara. International Journal of Development Research, 7(7), 13606-13611. Retrieved from http://www.journalijdr.com/sites/def ault/files/issue-pdf/9171.pdf

Ningrum, E (2016). Pengembangan Sumber Daya Manusia Bidang Pendidikan. Jurnal Geografi GEA Vol 9 No. 1

Sudrajat, 2008. Penelitian Tindakan Kelas.

http://akhmadsudrajat.wordpress.co m/2008/03/21/penelitian-tindakankelas-part-ii/

Tritularsih ,Yustina \& Wahyudi Sutopo. (2017). Peran Keilmuan Teknik Industri Dalam Perkembangan Rantai Pasokan Menuju Era Industri 4.0. Seminar dan Konferensi Nasional IDEC 2017 Surakarta, 8-9 Mei 2017
Wardiah, Isna (2015). Proceeding from the International Conference on NAMES 2015: Improving The Quality Of Learning On Applied Mathematics III Subject Using STAD Cooperative Learning Model For Informatics Engineering Students At State Polytechnic Of Banjarmasin. Banjarmasin 
Isna Wardiah dan Nurmahaludin Inovasi dalam Pembelajaran... 